\title{
CONFUCIAN THOUGHTS WITHIN A CHILD FRIENDLY SCHOOL (CFS): A CASE STUDY IN CAMARINES NORTE, PHILIPPINES
}

\author{
Melanie G. Riva*, Kathryn Halili, Gladys Lazo and Renee Talavera \\ College of Education, University of the Philippines Diliman
}

\begin{abstract}
This qualitative descriptive study has examined a Child Friendly School (CFS) model visà-vis the Confucian philosophy in the Philippine education setting. CFS model is a child-centered framework curriculum design that is considered to be of western thought and which espouses a holistic philosophy of an inclusive, healthy and protective school environment for children. The contextualized adoption of CFS in one of the elementary public schools was examined through the Confucian tenets of a moral, holistic and self-actualized learning. This contextualization can have mismatch or misalignment especially on a case where the system was developed outside of the locale, such as the case of CFS. Thus, this paper has explored a child-friendly school in terms of its curriculum, practices, school policies and integrated programs that corresponds to the core elements of a CFS model in the case of Iraya Elementary School. Specifically, it responded to the questions: what are the features of Child Friendly School model that relates to a Confucian philosophy of education? What are the Child Friendly School practices of Iraya Elementary School? How is the Confucian philosophy reflected in the Child Friendly School practices of Iraya Elementary School? Data were gathered through survey, key informant interview and document analysis to examine how the Confucian philosophy of education is reflected in the CFS model. We concluded that although CFS originated from the west and Confucianism from the east, there exists congenial principles. The development of a whole child is an output of CFS with the Confucianism idea of perfection of a learner. Furthermore, the CFS upholds that education is a right and Confucius believes that everyone is educable and perfectible.
\end{abstract}

Keywords: Child-Friendly School, Confucian Philosophy, contextualization, child-centered, childseeking

\section{Introduction}

Education in the Philippines underwent different reforms as the country underwent different stages of development. Being one of the UN member countries, the Philippines adheres to the UN Convention on the Rights of the Children (UN-CRC). In effect, the Department of Education (DepEd) integrated the Child Friendly School (CFS) System in the Basic Education Reform Agenda (BESRA, DepEd Order No. 23, series of 2010). CFS is based on the UN-CRC. It is a model promoted by UNICEF for the achievement of the Declaration of Education for All by all UN member countries. The DepEd mission and vision resonates with the principles of CFS.

CFS espouses a holistic philosophy of an inclusive, healthy and protective school environment for all children, that is effective with children, and which allows involvement of the family, the community and the society. Philosophies are pivotal in guiding educational practitioners in designing and implementing a school curriculum. It serves to critically evaluate the aims, ideas, educational values and all the other elements of education linked to moral and social conditions. CFS is considered to be conceived by western thoughts and in the case of the Philippines, is applied in an eastern country, which might have differences in values, moral, and social conditions. 
The Confucian philosophy is an eastern philosophy, which influenced social values, traditions, and ways of thinking in eastern countries. This included the education system of some countries and communities in Asia. It espouses principles and life skills towards the development of a holistic learner. An aspect of Confucianism is the inculcation of humanity through holistic education. Eastern philosophies developed in an eastern society, reflective of the culture and values of eastern countries. CFS is of western origin, it is a model which can be contextualized in its application as it is being done in the Philippine basic education. This contextualization may be points of agreement with the eastern philosophy and CFS. It is in this context that it is assumed that a childfriendly school environment resonates with the Confucian thought of education. Thus, this paper will explore a child-friendly school in terms of its curriculum, practices, school policies and integrated programs that corresponds to the core elements of a CFS model. Moreover, the contextualized adoption of CFS in one of the elementary public schools was examined through the Confucian tenets of a moral, holistic and self-actualized learning. This contextualization can have mismatch or misalignment especially on a case where the system was developed outside of the locale, such as the case of CFS. It is examined in parallel to Confucianism which is commonly present in Asian communities. Agreements between the CFS contextualization and implementation practices with Confucianism could be a gauge of good integration. Disagreements could be inputs for review and re-design of implementation. No matter the case, the results of the study are inputs for the improvement of the CFS implementation.

To be able to examine in parallel Confucianism and CFS system, this descriptive qualitative study has examined the CFS adoption and implementation in terms of policies, plans, and practices within the local context of Iraya Elementary School in Camarines Norte, Philippines. Specifically, it responded to the questions: What are the features of Child Friendly School model that relates to a Confucian philosophy of education? What are the Child Friendly School practices of Iraya Elementary School? How is the Confucian philosophy reflected in the Child Friendly School practices of Iraya Elementary School?

\section{The Concept of CFS in the Lens of Confucian Philosophy}

The researchers tried reviewing literature related to the Child Friendly School that emanated from the Confucian philosophy of holistic education. Due to the lack of studies related to the investigation concerning Confucian philosophy and Child Friendly School, the authors utilized the studies below.

The researchers tried reviewing literature related to the Child Friendly School that emanated from the Confucian philosophy of holistic education. Due to the lack of studies related to the investigation concerning Confucian philosophy and Child Friendly School, the authors utilized the studies below.

Two strong attributes describe a CFS model: it is child-seeking and it is child-centered. Child-seeking articulates inclusion and recognition of diversity of learners, irrespective of gender, race, ability and social status. Childcentered means that schools should act in the best interest of the child, leading to the realization of the child's potential in terms of health and well-being. Further, the concept fosters a holistic approach in a sense that, it recognizes the child's well-being at school, at home and within the community. It puts strong emphasis on the welfare of the child before they enter school and after they leave the school.

While the concept of CFS has been conceived through western thoughts and culture that have often stressed independence and individuality, it can be noted that its dimensions distinctly articulates a Confucian thought of developing an exemplary individual defined by social relations. Confucian philosophy on education demonstrates a positive view that everyone is educable and perfectible (Analects, 15.38 trans by Legge, 1971). Its methods emphasize learning from exemplars, environmental conditions, community practices, and cultivation of moral responsibility and social commitment (Leung, 1998), which can be said to outline the rights-based principles of a child friendly school. 
Examining the five dimensions of a CFS model to the educational aims of Confucian philosophy provides broader elucidation of the commonalities and intersections of a Confucian thought on education. Notable is the participation of children, parents and the local community as a major CFS dimension and which is in consonant with the Confucian emphasis on social relations which according to Sim (2009), stems from the fact that human life is not simply individual, positing that "a person is always intertwined in a web of relations and is defined by roles". A Confucian philosophy sees human beings as organic and networked-base entity that are interconnected with each other, with the family, community and the society, thus, making sense of self-identity through understanding of one's position in relation to others. From the words of Tu (as cited in Ryu, 2008), "the Confucian self is a center of relationships rather than an isolated being", of which is, evocative of the Confucian tradition, "juzi" or the maintenance of radical dependence upon others, that can be considered as an exemplar actualization of one's ascribed roles.

The focus of CFS to serve as the standard for a quality basic education, is framed within the holistic philosophy and child-centered pedagogy that aims "to produce independent thinkers who can make constructive contributions to a participatory democracy, able to adapt to changing circumstances" (UNICEF). This "whole child' development as an expected outcome of a CFS model, resonates with the Confucian thought of "actualization or perfection of learner" (Flanagan, 2011). For Confucius, the ultimate goal of learning was to cultivate a man of superior intellectual and moral qualities.

Borrowing from the words of Charlene Tan (2017), the Confucian aim of education is to inculcate ren (humanity) through $l i$ (normative behaviors) so that learners can realize and broaden dao (way). This necessitates for a holistic, broad-based, and integrated curriculum where students are nurtured to constantly practice what they have learned through self-cultivation and social interaction. Supporting the curriculum is the need for a learner-focused education, where the teacher is sensitive to the individual needs of students. The "enlightening approach" is therefore construed as parallel to the CFS goal of quality education, where teachers encourage and guide students to become independent thinkers who are able to create constructive contributions to a participatory democracy and able to adapt to changing circumstances.

\section{Conceptual Framework}

This study is conversant of Tosam's (2016) symbiotic relationship between philosophy and culture, wherein philosophy emerges as a reaction to, or as justification for a particular culture which is the reason why philosophy may differ from one culture to another. From the words of Tosam (2016), "philosophy is the means by which every culture provides itself with justification for its values, beliefs, and worldview, and also serves as the catalyst for progress. Philosophy helps to liberate the individual from the imprisonment of ignorance, prejudice, superstition, narrow-mindedness, and the despotism of custom". Philosophy of education addresses the philosophical questions concerning the nature, aims, and problems of education. Education practitioners look inward to the parent discipline of philosophy and outward to educational practice (Siegel, 2009). 


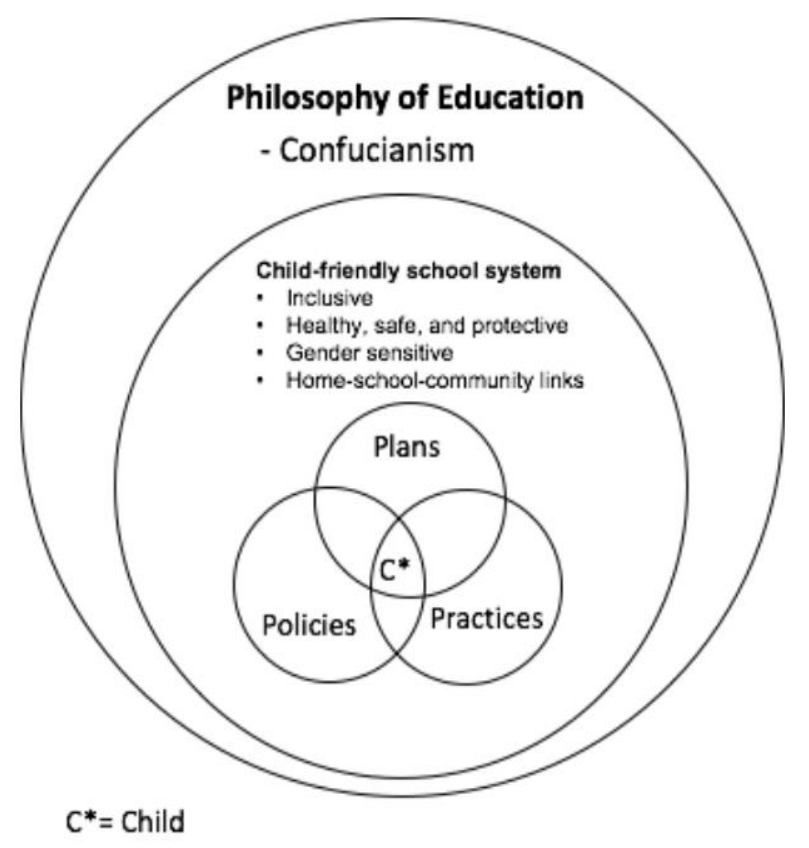

The CFS framework is a "pathways towards quality" education (UNICEF, 2009) wherein the concepts and models serves as guidelines for a contextualized implementation. CFS key principles of child-centeredness, democratic participation and inclusiveness are based from the core ideologies of the UN Convention on the Rights of a Child (UN CRC). These will "move schools towards provision of quality education" (UNICEF, 2009) as they improve on the application of these principles. CFS system do not work on itself but has to be contextualized to the particular culture of the society of implementation.

The philosophy of education in a particular society is based or inspired by a particular philosophy as illustrated in Figure 1. The different aspects of the CFS system is developed and implemented as it is interpreted by the values from the adopted philosophy, the biggest circle. The plans, policies, and practices are developed based on the different aspects of the CFS system. The objective of all these is the learning and development of the child at the center. A contextualized CFS is significant because the different aspects in the life of a child is considered to be affected within the school, within the family and within the community. These social factors should be aligned for continuity and unity in the development of the child. Values applied in school, at home, and in the community is one of the philosophies that CFS upholds.

\section{Method}

This case study has been undertaken in one of the local schools in the province of Camarines Norte, Philippines, during the second and third quarter of school year 2018-2019. Data were gathered through survey, key informant interview and analysis of school policy documents to examine how the Confucian philosophy of education is reflected in the CFS model in terms of the school's policies, practices, programs and plans. An open-ended interview guide was used in determining the plans, practices, and policies of Iraya Elementary School.

The interview guide was based on the CFS Survey (DepEd Order No. 44, series of 2015) which indicated the following specific goals: 1) encourage children's participation in school and community; 2) enhance children's health and well-being; 3) guarantee safe and protective spaces for children; 4) encourage enrollment and competition; 5) ensure children's high academic achievement and success; 6) raise teachers' morale and motivation; and 7) mobilize community support for education. Document analysis was done on pertinent school 
policies and report on practices and activities. Key informant interviews were conducted with the school's stakeholders: the school's CFS coordinator who was concurrently a class adviser and health coordinator of the school, a parent who is a GPTA (General Parents Teachers Association) member, a pupil who is currently the president of the school's Supreme Pupil Government (SPG), and the barangay chairman of the community.

The school was selected out of convenience because CFS implementation was with select schools only. The interview respondents were identified as those directly involved in the CFS implementation. They represent the major stakeholders in the school and community. Data collection was done in the first half of the school year 2018-2019. The conduct of the study was in coordination with pertinent DepEd authority in the area. Respondents were oriented with the purpose of the study prior to the conduct of the interview. Parental consent and ethical considerations were employed during the conduct of interview with the child-respondent.

\section{Results and Discussions}

The features of the CFS that is concomitant with Confucian philosophy of education rests on the goal of CFS to transform the learners holistically through education and the belief of Confucian philosophy that the curriculum in school should be holistic and broad-based. This shows the critical role of developing and adopting a curriculum model that will address the holistic development of learners. Another characteristic of CFS that is connected with Confucian philosophy of education is the notion that the learner, the teacher, the parents and whole community should work together in creating learning opportunities and supporting a learner-conducive environment. The involvement of all stakeholders in the realization of the CFS goals is in parallel with the Confucian emphasis on social relations and humanism, and placing high value upon family-oriented moral qualities (O'Dwyer, 2003). Humanism is considered as the cardinal principle of Confucianism which according to Yum (2009), is understood as a warm human feeling between people but which equally values reciprocity. Humanism and reciprocity can be seen as integral aspects of a child friendly school as it requires the harmonious social relations between stakeholders to work together in order to achieve its purpose of helping a child to develop to his or her full potential.

Confucian philosophy of education views the cultivation of self and social interaction as essentials of the total development of individuals. From a Confucian thought, morality is a principle of cultivation, practice and action; it has the power of transforming an individual into a moral being which implies that, self-realization is achievable through interaction with one's natural and social environment (Wen Ma, 2009; Wang, 2004). The holistic development of a learner only becomes possible with appropriate social interaction and the involvement of the different groups in the community where he or she belongs. It is therefore imperative to establish strong connections among family, school, and community to enrich the social interaction of a learner.

In establishing a democratic participation in school, CFS banks on promoting fair policies and services, and nondiscrimination and participation. This is related with the educational belief of Confucianism that a learnerfocused environment happens when the teacher is sensitive to the individual differences and needs of students. The idea of participation is connected with the 'enlightening approach' of Confucian education which recognizes the paramount role of the teacher to encourage and guide the students through questioning technique and involvement of peer learning. The same principle is found in the CFS' inclusiveness, indicating that the school must be seeking, welcoming for all students, is gender-sensitive, and armed with policies and services that encourage attendance and retention.

\section{Contextualizing the CFS model: The case of Iraya Elementary School}

The CFS element of maintaining a healthy, safe and protective environment for children is explicitly practiced at Iraya Elementary School. The school maintains a monthly coordination with the Camarines Norte DepEd Medical Team to address the pupils' health and oral hygiene. The program includes quarterly dental examination with oral prophylaxis. To ensure that all pupils are physically sound, the school implements a bi- 
annual monitoring of the children's weight and height, and other body measurements, as a form of nutritional assessment. Compliant to DepEd's supplemental guidelines on the implementation of a school-based feeding program (Department Order No 15, S. 2018), Iraya Elementary School is actively engaged in making sure that malnourished children from Grades 1 to 6 undergoes a feeding program for a duration of one year. In terms of policy, the school canteen strictly adheres to, and observes the guideline of providing nutritious food to the grade schoolers. Teacher engagement in this program is through scheduled monitoring and policy assessment. Moreover, street vendors along and outside the school premises, and who are non-compliant to the school policy, are prohibited to engage in any form of food selling activities.

The school's strong focus on children's health and nutrition is also observable in the school projects and events such as the school gardening program (Gulayan sa Paaralan), observance of the National Handwashing Day, which is a flagship program of United Nations (UN) and the Department of Health, celebration of Nutrition Month, and maintenance of school toilets. The participation of parents and community is relatively important in the realization of the CFS goals. In the context of Iraya Elementary School, the active participation of parents through the Homeroom Parents Teachers Association (HPTA) and the community's collaborative effort is contributory to the realization and sustenance of school projects and programs.

Interestingly, the school has cited the existence of a 'Supreme Pupil Government' which is considered to be the highest form of student organization in the school along with the other school clubs such as the English, Filipino, Math, Science, Girl Scout and Boy Scout among others. The Supreme Pupil Government serves as an institutionalized, children-led and school-based organization that functions as a mini- government within the school. This school children organization is directly involved in the school's policy-making processes, curriculum implementation and civic education programs. Children's participation is in the form of proposals, program initiatives and participation in specific meetings and planning sessions that concern their well-being. The organization's activities are governed by its own constitution and by-laws. As mandated by the Department of Education, the school is reciprocally cognizant of this children-led organization and are responsive in terms of implementation. The active participation of children through the Supreme Pupil Government forms a significant connection to the child-rights approach of CFS. It is as well congenial with the Confucian thought of the moral education of man, which is distinctly, the hallmark of Confucian philosophy. As stated by Lind (2006), democracy is a moral ideal of how people can live and work together in peace.

Other school practices that involved children's participation and establishes home, school and community links are the Disaster Risk Reduction and Management club, the medical mission and community giving, and the tree planting and community cleaning. Central to Iraya Elementary School's set of plans is the achievement of a gender-sensitive school environment. As of this writing, a set of gender mainstreaming activities were lined up for implementation: establishment of a gender desk, gender policy distributed and school awareness campaigns, facilitation of teacher training programs on gender equality and sensitivity, adoption of a gender-neutral language, installation of a common toilet and the maintenance of a classroom seat plan that supports equal participation.

\section{Conclusion}

The Confucian philosophy of education is reflected in the Child Friendly School (CFS) model as examined in our research. DepEd adopted the CFS system since 2001 to improve the quality of education in the Philippines. The research was done through interviews with students, school representative, parent, and community on the plans, policies, and practices using the DepEd CFS Survey. The survey expounded on the goals of CFS system of DepEd to connect it to the key features of CFS model of UNICEF. Although CFS originated from the west and Confucianism from the east, there exists congenial principles, which has been explored in this study. At the root of this is the importance given to education, CFS upholds that education is a right and Confucianism believes that everyone is educable and perfectible. This leads to the same feature of a child-centered education. 
The development of a whole child is an output of CFS which is in consonance to the Confucianism idea of actualization or perfection of the learner. CFS as it was developed in the west stressed independence and individuality as compared to the development of individuals through social relations in Confucianism, but both gives importance to the involvement of the family and the community for a child's learning and development.

The result illustrated one of the differences of the eastern and western philosophies in general. Western philosophies focus on individuals while eastern philosophies look at development collectively, that is in relation with others. The CFS implementation adapted this difference by focusing more on the involvement of not only the school community but also of the family and the social community in school activities. In CFS, teachers are facilitators which is of different perspective with Confucianism wherein teachers are more of model who students follow as they look up to them. In the contextualization of CFS, teacher facilitation was presented as collaborative participation with the parents and community for the child's development. Contextualization is important or at least an understanding of local practices is needed to adapt systems not of local origin such as the CFS system. Finding the common ground is significant for ease in integration. At the end of the day, what is important, no matter the philosophy or system is in application, is that children are helped to do more productive learning and develop their potentials to be good citizens.

It is being recommended that the following people like teachers, administrators, parents, students and other stakeholders in the community should promote the use of a Child Friendly School in their school curriculum design in order to foster the integration of the ideas of Confucius being an oriental philosophy. The in-school and off-school experiences of the learners should be designed to integrate the salient features of a Child Friendly School and Confucian philosophy of education.

\section{Acknowledgement}

We extend special thanks to our professor in philosophy of education, Dr. Maricris Acido-Muega, of the College of Education, University of the Philippines Diliman, for her invaluable lectures and encouragement that inspired us to do this work.

\section{References}

Department of Education (DepEd). Basic Education Sector Reform Agenda (DepEd Order No. 23, series of 2010). DepEd, Philippines.

Flanagan, F.M. (2011). Confucius, the Analects and western education. London: Continuum International Publishing Group.

Legge, J. (1971). Confucius: Confucian Analects, the great learning and the doctrine of mean. New York: Dover Publications, Inc.

Leung, F.K.S. (1998). The implications of Confucianism for education today. Journal of Thought, 33(2), pp.2536. doi: 42590239

Lind, G. (2006). Perspektive 'Moralisches und demokratisches Lernen [Perspective ,moral and democratic learning']. In A. Fritz, R. Klupsch-Sahlmann \& G. Ricken, (Eds.), Handbuch Kindheit und Schule. Neue Kindheit, neues Lernen, neuer Unterricht, 296-309. Weinheim: Beltz.

O’Dwyer, S. (2003). Democracy and Confucian values. Philosophy of East and West, 53(1), pp. 39-63. Retrieved from http://www.jstor.org/stable/1400054

Ryu, K. (2008). The teachings of Confucius: A humanistic adult education perspective, "Adult Education Research Conference. http://newprairiepress.org/aerc/2008/papers/57

Shaohua Hu (1997). Confucianism and western democracy. Journal of Contemporary China, 6(15), pp. $347-363$. doi: 10.1080/10670569708724282

Sim, M. (2009). Dewey and Confucius: On moral education. Journal of Chinese Philosophy. Retrieved from http://enlight.lib.ntu.edu.tw/FULLTEXT/JR- AN/an176659.pdf 
Tan, C. (2017). Confucianism and education. In Noblit, G. (Ed.), Oxford Research Encyclopedia of Education (pp. 1-18). New York: Oxford University Press.

Tosam, J.M. and Takov, P. (2016). Philosophy in culture: A cross-cultural perspective. Cameroon: Langaa Research and Publishing Common Initiative Group.

UNICEF. $\quad$ Child-Friendly $\quad$ School. $\quad$ Retrieved from https://www.unicef.org/publications/files/Child_Friendly_Schools_Manual_EN_040809.pdf

UNICEF (2009). Child Friendly Schools evaluation: Country report for Philippines. Retrieved from https://www.unicef.org/evaldatabase/files/Philippines_CFS_Report_5.10.10.pdf

Wang Fengyan (2004). Confucian thinking in traditional moral education: Key ideas and fundamental features. Journal of Moral Education, 33(4), pp. 29-447. doi: 10.1080/0305724042000327984

Wen Ma (2009). Self-realization in John Dewey and Confucius: Its philosophical and educational feature (master's thesis). Retrieved from http://citeseerx.ist.psu.edu/viewdoc/download?doi=10.1.1.526.4664\&rep=rep1\&type=pdf

Yum, J.O. (2009). The impact of Confucianism on interpersonal relationships and communication patterns in east Asia. Communication Monographs 55(4), pp. 374-388. https://doi.org/10.1080/03637758809376178 